\title{
QUALITY OF LIFE OF MIDWIVES WORKING IN CLINICS AND MATERNITY HOSPITALS IN NORTHWEST IRAN
}

\author{
Arman Latifi' ${ }^{1}$,Mehri Alaviani², Mahbobeh Fath-Imani ${ }^{3}$, Mehdi Khezeli', Fattane Karimi ${ }^{5}$ \\ ${ }_{1}^{1}$ Assistant Professor, Department of Public Health, Maragheh University of Medical Sciences, Maragheh, Iran. \\ ${ }^{2}$ Msc, School of Nursing, Lecturer, Patients Safety Research Center, Urmia University of Medical Sciences, Urmia, Iran. \\ ${ }_{3}^{3}$ BSc, Mashhad University of Medical Sciences, Mashhad, Iran. \\ ${ }_{4}^{4} \mathrm{PhD}$, Research Center for Environmental Determinants of Health, Kermanshah University of Medical Sciences, Kermanshah, Iran. \\ ${ }_{5}^{5}$ Sc, School of Nursing and Midwifery, Maragheh University of Medical Sciences, Maragheh, Iran.
}

\begin{abstract}
BACKGROUND

Quality of Life is a personal interpretation about the life status in the context of culture and value system. The quality of life of midwives working in the health care system requires special attention.

The present study was conducted with an aim to investigate the quality of life of midwives working in clinics and maternity hospitals in northwest of Iran.
\end{abstract}

\section{MATERIALS AND METHODS}

This cross-sectional study was conducted with participation of 70 midwives working in health centers and maternity hospitals in Maragheh. The data collection tool in the present study was Quality of Life Quality Questionnaire of the World Health Organi zation (WHOQOL-BREF-26). The collected data was analysed using software SPSS version 16 and Kruskal-Wallis, Mann-Whitney and Pearson correlation descriptive tests. The significance level was considered 0.05 .

\section{RESULTS}

The mean age of the subjects was 31.18 years with a standard deviation of 7.74 . The mean and standard deviation of the overall quality of life score was $74.54 \pm 17.06$ from 100 . The highest and lowest scores were related to the domain of the physical health $(71.34 \pm 14.14)$ and environmental health $(61.77 \pm 14.87)$, respectively. A significant difference was found between the mean scores of the domains of the quality of life and employment type. Spearman correlation test showed that a statistically significant correlation was found between the physical health, mental health and total score of quality of life and age.

\section{CONCLUSION}

The results of the present study showed that the average quality of life score of subjects was higher than mean and was moderate. It is suggested that midwives receive training on the factors affecting the quality of life to become empowered to enhance their quality of life and the health of themselves and their clients.

\section{KEY WORDS}

Mental Health, Midwife, Quality of Life.

HOW TO CITE THIS ARTICLE: Latifi A, Alaviani M, Fath-Imani M, et al. Quality of life of midwives working in clinics and maternity hospitals in northwest Iran. J. Evolution Med. Dent. Sci. 2018;7(35):3906-3909, DOI: 10.14260/jemds/2018/873

\section{BACKGROUND}

The World Health Organization defines the Quality of Life as the personal interpretation about his life status in the context of the culture and value system in which he lives.(1) These experiences are unique and presented within the scope of the personal life such as marriage, occupation, health etc. The satisfaction or dissatisfaction with the experiences results from the coordination or lack of coordination between current situations and expected and desired situations. (2)

For the quality of life six domains have been expressed that include the physical health, mental status, levels of autonomy, social communication, environmental communication and spiritual interests. Different aspects affect the quality of life and these aspects include

'Financial or Other Competing Interest': None.

Submission 10-07-2018, Peer Review 10-08-2018,

Acceptance 17-08-2018, Published 27-08-2018.

Corresponding Author:

Fattane Karimi,

School of Nursing and Midwifery,

Maragheh University of Medical Sciences, Maragheh, Iran

E-mail: fattanehkarimi1395@gmail.com

DOI: $10.14260 /$ jemds $/ 2018 / 873$ socioeconomic, psychological and occupational status.(3) One of the factors affecting the quality of life is working. Accordingly, the great work effects and the imbalance between work time and personal and family life have put the quality of life of many people and families at high risk.(4) Although, the work is a very important source for the life and acquiring social positions can at the same time lead to dissatisfaction and reduction of physical and psychological forces.(5) Some works are associated with many physical and psychological stresses, and this is due to the nature of the work, the type of tasks and responsibilities. The members of the medical team are those who receive a high level of these pressures. Since midwives are also part of this team, stressors can be considered as psychological or psychosocial threats.(6) Midwives play an important role in the public health at the three levels of the health care system including the hospital and the family and community health center. According to the statistics of Ministry of Health and Treatment, the number of midwives in different centers is about 15,000.(7) The conducted studies in the country have provided a variety of assessments of the quality of life of nurses and midwives, some reported good quality of life(8) and some reported undesired quality of life.(9) Also studies in 
other parts of the world have shown that the quality of life in the South African nursing profession is lower than their American counterparts. The nurses had a high level of selfconfidence and self-esteem in nurses was directly and indirectly influenced by their job satisfaction.(10) However, the results of previous studies indicate a positive and significant correlation between the quality of work life and job performance.(11-13) The midwives working in the health care system due to the importance of this profession and their responsibility in protecting the life of the mother and child should be given more attention. One of the important issues in their life is their quality of life. Therefore, the present study has been conducted to evaluate the quality of life of midwives working in clinics and maternity hospitals in northwest of Iran.

\section{MATERIALS AND METHODS}

This study was a cross-sectional study. The study population included all midwives working in health centers (a total of 9 centers) and maternity hospitals in Maragheh. A total of 70 midwives working in these centers participated in this study. The inclusion criteria included all employed midwives with at least associate degree and one year of work experience and dissatisfaction with participation in the study were among the exclusion criteria.

The data collection tool in the present study was Quality of Life Quality Questionnaire of the World Health Organization (WHOQOL-BREF-26).(14) This tool examines individual's satisfaction with life and records the positive and negative aspects of the quality of life.(14) The questionnaire consists of two parts: the first part of the questionnaire related to the individual and occupational characteristics of the subjects: age, marital status, educational level, place of employment, type of employment, work experience and the second part of the questionnaire related to the quality of life including four aspects of the physical, psychological, social and environmental. The questionnaire has a total of 26 questions and the scoring scale is based on a 5-point Likert scale, in which 1 indicates the negative and low perception and 5 indicates the positive and high perception. After making the necessary calculations in each field a score of 420 is obtained for each field, in which 4 is the worst and 20 is the best status for the quality of life in the given field.(15) This questionnaire has been translated and validated in more than 40 countries, and also in Iran its validity and reliability have been verified.(15) The questionnaires were provided to the subjects at least for 24 hours in order to be able to respond to the questions in a relaxed and appropriate environment with no occupational and environmental stresses. In the present study we met the ethical issues such as explaining the purpose of research and ensuring women from the confidentiality of information. Also, written informed consent form was obtained from participants. The collected data were analysed using software SPSS version 16 and Kruskal-Wallis, Mann-Whitney and Pearson correlation descriptive tests. The significance level was considered 0.05 .

\section{RESULTS}

The results of the data analysis showed that the mean age of the subjects was 31.18 years with a standard deviation of 7.74; 26 (31.7\%) participants were single and 56 (68.3\%) were married; 10 (12.2\%) participants had a diploma degree; $68(82.9 \%)$ had a bachelor's degree and $4(4.9 \%)$ had a master's degree. 34 (41.5\%) participants worked in the maternity hospital, 24 (29.3\%) worked in clinics, 20 (24.4\%) were office staff and $4(4.8 \%)$ participants were faculty members. For the type of employment 20 (24.4\%) participants were seasonal, $47(57.3 \%)$ were semicontractual, $5(6.1 \%)$ were contractual and $10(12.2 \%)$ were formal. $20(24.4 \%)$ participants in the study had an office. The average work experience of the participants in the study was 6.32 and the standard deviation was 6.61.

The mean and standard deviation of the overall quality of life score was $74.54 \pm 17.06$ from 100 . The highest and lowest scores were related to the domain of the physical health (71.34 \pm 14.14$)$ and environmental health $(61.77 \pm 14.87)$, respectively (Table 1 ).

In examining the relationship between different domains of the quality of life and workplace variables, level of education, marital status and having a personal office, the results showed that no statistically significant difference was found ( $p>0.05$ ), but a significant difference was found between the mean scores of the domains of the quality of life and employment type. So that the quality of life score in all domains for those with seasonal type of employment was more than others $(p=0.01)$. The more detailed information are given in (Table 2).

Also, Spearman correlation test showed that statistically a significant correlation was found between the physical health, mental health and total score of quality of life and age. Also, statistically a significant correlation was found between all domains of the quality of life except the social health and work experience (Table 3).

\begin{tabular}{|c|c|c|c|c|c|c|c|}
\hline \multirow{2}{*}{\multicolumn{2}{|c|}{ Variables }} & \multicolumn{5}{|c|}{$\begin{array}{c}\text { Quality of Life Domains } \\
\text { Mean (SD) }\end{array}$} & \multirow[t]{2}{*}{ p } \\
\hline & & Physical & Mental & Social & Environmental & Total & \\
\hline \multirow{4}{*}{ Workplace } & Maternity & $71.32 \pm 14.85$ & $67.52 \pm 15.06$ & $68.62 \pm 17.17$ & $62.59 \pm 13.40$ & $78.67 \pm 16.43$ & \multirow{4}{*}{ NS } \\
\hline & Clinic & $72.17 \pm 14.20$ & $64.75 \pm 11.52$ & $70.46 \pm 14.32$ & $63.93 \pm 16.86$ & $71.35 \pm 17.08$ & \\
\hline & Office staff & $69.64 \pm 12.77$ & $63.75 \pm 10.90$ & $63.75 \pm 16.94$ & $58.90 \pm 13.38$ & $72.50 \pm 13.81$ & \\
\hline & Faculty member & $76.78 \pm 18.09$ & $68.75 \pm 13.81$ & $47.91 \pm 18.47$ & $56.25 \pm 23.24$ & $68.75 \pm 33.07$ & \\
\hline \multirow{3}{*}{ Education } & Associate & $69.64 \pm 14.50$ & $68.75 \pm 11.56$ & $68.33 \pm 7.68$ & $64.37 \pm 7.68$ & $77.50 \pm 14.19$ & \multirow{3}{*}{ NS } \\
\hline & Bachelor & $71.79 \pm 14.42$ & $65.31 \pm 13.43$ & $68.01 \pm 16.88$ & $62.04 \pm 15.22$ & $74.63 \pm 16.58$ & \\
\hline & Master & $67.85 \pm 9.67$ & $67.70 \pm 13.76$ & $45.83 \pm 15.95$ & $78.50 \pm 20.78$ & $65.62 \pm 31.25$ & \\
\hline \multirow{2}{*}{ Marital status } & Single & $72.93 \pm 13.06$ & $67.46 \pm 13.07$ & $65.38 \pm 16.61$ & $65.26 \pm 13.61$ & $75.96 \pm 16.55$ & \multirow{2}{*}{ NS } \\
\hline & Married & $70.59 \pm 14.67$ & $65.10 \pm 12.97$ & $67.70 \pm 17.04$ & $60.15 \pm 15.26$ & $73.88 \pm 17.39$ & \\
\hline \multirow[b]{2}{*}{ Employment } & Seasonal & $73.39 \pm 11.78$ & $71.66 \pm 12.72$ & $73.75 \pm 12.51$ & $68.87 \pm 12.51$ & $84.37 \pm 9.82$ & \multirow[b]{2}{*}{$\underline{0.01}$} \\
\hline & $\begin{array}{c}\text { Semi- } \\
\text { Contractual }\end{array}$ & $71.96 \pm 15.26$ & $64.89 \pm 12.84$ & $65.07 \pm 18.44$ & $60.10 \pm 16.94$ & $70.74 \pm 20.19$ & \\
\hline
\end{tabular}




\begin{tabular}{|c|c|c|c|c|c|c|c|}
\hline & Contractual & $73.57 \pm 12.52$ & $60.83 \pm 14.61$ & $60.00 \pm 16.02$ & $64.37 \pm 3.56$ & $72.50 \pm 16.29$ & \\
\hline & Formal & $63.21 \pm 12.60$ & $61.25 \pm 10.76$ & $65.83 \pm 12.07$ & $58.12 \pm 9.79$ & $73.75 \pm 10.75$ & \\
\hline \multirow{2}{*}{ Personal office } & Yes & $73.12 \pm 16.85$ & $62.22 \pm 16.48$ & $71.92 \pm 15.26$ & $64.30 \pm 16.21$ & $73.68 \pm 22.78$ & \multirow{2}{*}{ NS } \\
\hline & No & $70.80 \pm 13.32$ & $65.74 \pm 11.86$ & $65.47 \pm 17.12$ & $61.01 \pm 14.49$ & $74.80 \pm 15.14$ & \\
\hline
\end{tabular}

\begin{tabular}{|c|c|c|}
\hline Quality of life Domain & Age & Job Experience \\
\hline Physical Health & $*_{-} .243$ & $*_{-} .227$ \\
\hline Mental Health & $*_{-}-.285$ & -.181 \\
\hline Social Health & -.207 & ${ }_{-} .259$ \\
\hline Environmental Health & .179 & $*_{-} .345$ \\
\hline Total Quality of Life & $* * .312$ & \\
\hline \multicolumn{2}{|r}{} \\
\hline
\end{tabular}

${ }^{*} \mathrm{p}<0 / 05,{ }^{* *} \mathrm{p}<0 / 01$

\begin{tabular}{|c|c|c|}
\hline Quality of Life Domain & Mean & Standard Deviation \\
\hline Physical Health & 71.34 & 14.14 \\
\hline Mental Health & 65.85 & 12.97 \\
\hline Social Health & 66.97 & 16.84 \\
\hline Environmental Health & 61.77 & 14.87 \\
\hline Total Quality of Life & 74.54 & 17.06 \\
\hline \multicolumn{2}{|c|}{ Table 3. Mean and Standard Deviation of Quality of Life Score } \\
\hline
\end{tabular}

\section{DISCUSSION}

The results of the present study showed that the average quality of life score of subjects was higher than mean and was moderate. On the one hand, the highest score was related to the physical health and the lowest score was related to the environmental health. This finding is consistent with the results of other studies. ${ }^{(16,17)}$ For example, the results of other studies showed that Iranian nurses had the lowest score in the quality of life in the mental health. ${ }^{18)}$ On the other hand, in explaining why in the present study the lowest score is related to the environmental health, it can be said that there are issues such as the work environment and organizational climate, and conflicts of interest with colleagues and authorities may lead to this. If organizations can increase the quality of work life of employees and create conditions in the workplace so that they feel the justice, equality, growth and opportunity to develop their capabilities, then we can witness the increased organizational commitment and consequently the growth and dynamism of the organisation.(19)

The results also showed that no significant difference was found between the mean of different domains of the quality of life and workplace variables, level of education, marital status and having a personal office and a significant difference was observed in terms of the employment type variable. The results of other studies also support these findings.(20-22) It is expected that the quality of life is higher for those with formal employment type and high job security as well as higher salaries, but the results were quite the opposite, and in those with seasonal employment type the quality of life score was higher than in all domains. The reason for this inconsistency may be that these are younger, more motivated and more enthusiastic to work and those with more work experience may have somewhat a burnout. Also, those with seasonal employment type are not limited to one sector or organization, they feel more freedom and if they have a better job opportunity they will choose it. Although, previous studies have argued that when employees are formal, they are confident that they will work for a long time in the organization. This makes them feel more attached and committed to the organization. $(21,23)$

Also, the results showed that statistically a significant correlation was found between the physical health, mental health and total quality of life scores with age and the quality of life score reduced with increasing age. This finding can be due to the effect of the health aspect on other aspects, as with increasing age the physical function and agility reduced. This finding is consistent with others' results.(23-25) Also, statistically a significant correlation was found between all aspects of the quality of life except social health and work experience. In explaining this finding, we can also say that work experience and age are correlated, and the longer work experience means the older age, and therefore all the reasons mentioned for the increase of age are also true in this case. Also, the increase in work experience is probably related to the formal type of employment that was associated with reduced quality of life.

\section{CONCLUSION}

Performing psychosocial and behavioural interventions in the midwifery workplace as well as removing barriers and discrimination between individuals in terms of the type of employment and job description can play a significant role in improving the quality of life of a midwife. Organizational interventions such as creating supportive environments and flexible work shifts will be other factors. And finally, it is suggested that midwives receive necessary training on the factors affecting the quality of life. Because of this training, they can try to enhance their quality of life and the health of themselves and their clients.

\section{REFERENCES}

[1] Theofilou P. Quality of life: definition and measurement. Europe's Journal of Psychology 2013;9(1):150-62. 
[2] Cummins RA. Moving from the quality of life concept to a theory. Journal of Intellectual Disability Research 2005;49(Pt 10):699-706.

[3] King IM. Quality of life and goal attainment. Nursing Science Quarterly 1994;7(1):29-32.

[4] Knezevic B, Milosevic M, Golubic R, et al. Work-related stress and work ability among Croatian university hospital midwives. Midwifery 2011;27(2):146-53.

[5] Todd CJ, Farquhar MC, Camilleri-Ferrante C. Team midwifery: the views and job satisfaction of midwives. Midwifery 1998;14(4):214-24.

[6] Mizuno M, Kinefuchi E, Kimura R, et al. Professional quality of life of Japanese nurses/midwives providing abortion/childbirth care. Nursing Ethics 2013;20(5):539-50.

[7] National Congress on Position of Midwifery Occupation in Community 2008, Tehran, Iran [Persian].

[8] MOH. Ministry of Health and Medical Education. Office of health. Office of informatics. http://it.behdasht.gov.ir.2016.

[9] Khoshknab FM, Karimloo M, Rahgoy A, et al. Quality of life and factors related to it among psychiatric nurses in the university teaching hospitals in Tehran. Hakim Research Journal 2007;9:24-30. [Persian]

[10] Babazadeh R, Mirzaii KH. Survey of emotional health on midwives and nurses who working in government hospitals in Mashhad. National Congress of quality of life and health promotion. Chahbahar, 2011.

[11] Pillay R. Work satisfaction of professional nurses in South Africa: a comparative analysis of the public and private sectors. Human Resources for Health 2009;7(1):15.

[12] Ryan B, Ma E, Hsiao A, et al. The work-family conflict of university foodservice managers: an exploratory study of its antecedents and consequences. Journal of Hospitality and Tourism Management 2015;22:10-8.

[13] Mauno S, Ruokolainen M, Kinnunen U. Work-family conflict and enrichment from the perspective of psychosocial resources: comparing Finnish healthcare workers by working schedules. Applied Ergonomics 2015;48:86-94.

[14] Sharma J, Dhar RL, Tyagi A. Stress as a mediator between work-family conflict and psychological health among the nursing staff: moderating role of emotional intelligence. Applied Nursing Research 2016;30:268-75.

[15] The WHOQOL Group. Development of the World Health Organization WHOQOL-BREF quality of life assessment. Psychological Medicine 1998;28(3):5518.
[16] Nedjat S, Montazeri A, Holakouie K, et al. Psychometric properties of the Iranian interview-administered version of the World Health Organization's Quality of Life Questionnaire (WHOQOL-BREF): a populationbased study. BMC Health Services Research 2008;8(1):61.

[17] Masoumi SZ, Mirzaiinajmabadi K, Shobeiri F, et al. Quality of life among midwives working in hospitals, in Hamedan, Iran. Payesh 2013;12(3):283-8.

[18] Rouleau D, Fournier P, Philibert A, et al. The effects of midwives' job satisfaction on burnout, intention to quit and turnover: a longitudinal study in Senegal. Human Resources for Health 2012;10(1):9.

[19] Mirmolaei T, Dargahi H, Kazemnejad A, et al. Job satisfaction of midwives. Journal of Hayat 2005;11(2):97-106. [Persian]

[20] Hosseini MS, Naderiyan M, Homaei R, et al. Relationship between quality of work life and organizational commitment of the Department of Isfahan Physical Education. Journal of Sport Management 2009;1(2):167-81.

[21] Saadoldin NSh, Talasaz Z, Shakeri MT, et al. Evaluation the relationship between occupational stress and happiness of midwives who work in hospitals and health centers in Mashhad. The Iranian Journal of Obstetrics, Gynecology and Infertility 2013;16(74):19. [Persian]

[22] Rouhi Gh, Asayesh H, Rahmani H, et al. Comparison of nurses' job satisfaction and organizational commitment in Intensive Care and General Wards of Golestan University of Medical Sciences. Scientific Journal of Gorgan Bouyesh Faculty of Nursing and Midwifery 2010;7(2):23-32. [Persian]

[23] Sakkaki M, Hajimiri K, Farsi F. Quality of work life among midwives working in Zanjan University of Medical Sciences Hospitals. Preventive Care in Nursing \& Midwifery Journal 2013;2(2):41-8.

[24] Howes CJ, Reid MC, Brandt C, et al. Exercise tolerance and quality of life in elderly patients with chronic atrial fibrillation. Journal of Cardiovascular Pharmacology and Therapeutics 2001;6(1):23-9.

[25] Paquette M, Roy D, Talajic M, et al. Role of gender and personality on quality-of-life impairment in intermittent atrial fibrillation. American Journal of Cardiology 2000;86(7):764-8. 